\title{
Correction to: Reluctant to embrace innocence: an experimental test of persevering culpability judgments on people's willingness to support reintegration services for exonerees
}

\author{
Kyle C. Scherr ${ }^{1}$ • Christopher J. Normile ${ }^{1}$. \\ Maria Camila Sarmiento ${ }^{1}$
}

Published online: 21 May 2018

(C) Springer Science+Business Media B.V., part of Springer Nature 2018

\section{Correction to: J Exp Criminol https://doi.org/10.1007/s11292-017-9306-2}

This correction provides minor changes to the original article-none of which alter the message of the research. The last update provides further clarity about the conditional indirect relationship.

- The statistics associated with the race $\mathrm{x}$ crime interaction supporting the CulpabilityConfidence Hypothesis are $F(1,167)=4.02, p=.047, \eta_{\mathrm{p}}{ }^{2}=.02$.

- The effect size statistics for the simple effect test comparing people's culpability confidence of the White to the African-American exoneree wrongfully accused of embezzlement should read, $d=.44,95 \%$ CI of $d[.02, .86]$.

- The confidence interval around the effect size for the simple effect test comparing people's culpability confidence of the White to the African-American exoneree wrongfully accused of physical assault should read, 95\% CI of $d[-.27, .61]$.

The online version of the original article can be found at https://doi.org/10.1007/s11292-017-9306-2

Kyle C. Scherr

kyle.scherr@cmich.edu

1 Department of Psychology, Central Michigan University, Sloan Hall 101, Mount Pleasant, MI 48859, USA 
- The statistics for the simple effect test comparing people's support of psychological counseling comparing the White to the African-American exoneree wrongfully accused of embezzlement should read, $F(1,167)=4.82, p=.03, d=.46,95 \%$ CI of $d[.03, .87]$.

- The statistics for the simple effect test comparing people's support of psychological counseling comparing the White to the African-American exoneree wrongfully accused of assault should read, $F(1,167)=0.60, p=.439, d=.18,95 \%$ CI of $d[-0.26,0.62]$.

- In Table 1, the mean for Culpability-Confidence Judgment under EmbezzlementWhite should be 6.17 .

- In Table 1, the standard deviation for Psychological Counseling under EmbezzlementAfrican American should be 2.17.

- Using an indirect conditional model that parallels the approach used for the ANOVA simple effect tests helps to bring more clarity to the results of the conditional indirect analysis. Specifically, still using Model 8 of PROCESS (Hayes, 2013), Frasier's race was treated as the predictor and the crime Frasier was wrongfully convicted of was used as the moderator (the mediator of culpability-confidence judgments and outcome of psychological counseling support remained the same). Providing evidence of moderated-mediation, results demonstrated that the race $\mathrm{x}$ crime interaction significantly predicted culpability-confidence judgments, point estimate $=-1.97, p=.047,95 \% \mathrm{CI}$ [-3.92, -.03] (mirroring the ANOVA results). Moreover, participants' culpabilityconfidence judgments were significantly associated with participants' willingness to support psychological counseling for Frasier, point estimate $=.15, p=.008,95 \%$ CI $[.04, .26]$. Critically, results demonstrated that when he was wrongfully convicted of embezzlement, participants were more reluctant to believe in Frasier's innocence when he was portrayed as White than as African-American which, in turn, undermined their willingness to support psychological counseling for Frasier, point estimate $=-.22$, $S E_{\text {bootstrap }}=.15,95 \% \mathrm{CI}_{\text {bootstrap }}=[-.603 ;-.012]$. However, results failed to support the idea that being wrongfully convicted of assault and being African-American, compared to White, indirectly undermined participants' willingness to support psychological counseling for Frasier via participants' reluctance to believe in Frasier's innocence, point estimate $=.08, S E_{\text {bootstrap }}=.11,95 \% \mathrm{CI}_{\text {bootstrap }}=[-.11 ; .34]$.

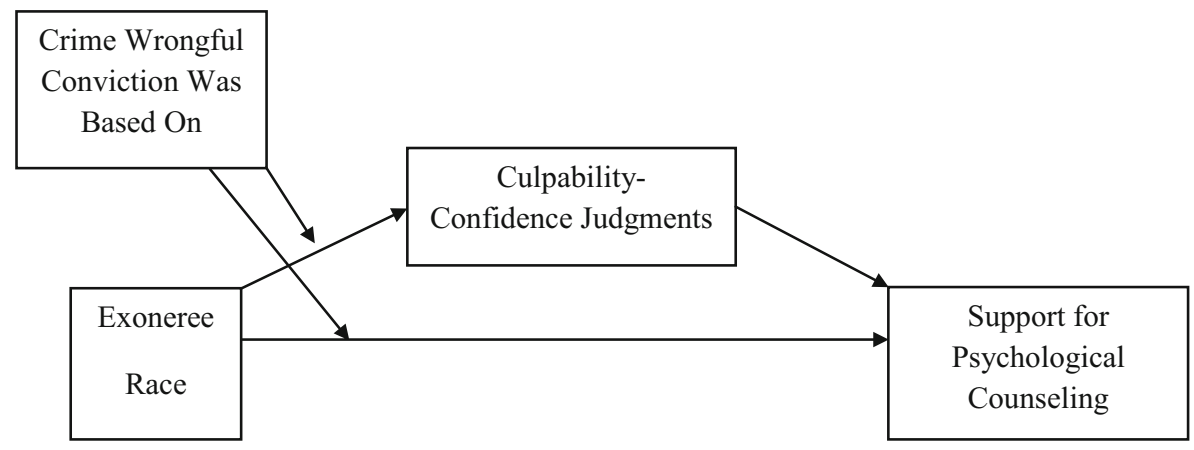

